\title{
I. Analysis of the chromate of iron from the ouralian mountains in Siberia
}

\section{A. Laugier}

To cite this article: A. Laugier (1806) I. Analysis of the chromate of iron from the ouralian mountains in Siberia, Philosophical Magazine Series 1, 24:93, 3-8, DOI: $10.1080 / 14786440608563323$

To link to this article: http://dx.doi.org/10.1080/14786440608563323

曲 Published online: 18 May 2009.

Submit your article to this journal $\lceil\pi$

Џll Article views: 2

Q View related articles $\square$ 


\section{PHILOSOPHICAL MAGAZINE.}

1. Analysis of the Chromate of Iron from the Ouralian Mountains in Siberia. By A. Lavgrer*.

M. Pontier, in a tour made through the department of Var, in the year 7, found, near La Bastide de la Cassade, a mineral, which he sent to the Council of Mines under the name of blende, and which M. Tassaert first discovered to be a combination of ohromic acid and oxide of iron.

His opinion was afterwards confirmed by M. Vauquelin in the tenth volume of the Journal de Mines; where he at the same time announced the proportions of chrome and iron, together with the presence of alumine and silica.

M. Meder has since found in Siberia, in the Ouralian mountains, on the banks of the Wiasga, a substance very similar to the mineral of Var. A specimen of this having been given to me by M. Steinacher, member of the corporation of apothecaries of Paris, who had received it from count Mussin Puschkin, counsellor of the mines of Russia, I conceived it might be useful to examine it, and compare the results of my examination with the analysis of the mineral of Var published by M. Vauquelin, fully persuaded that my labours would be rewarded with some advantage.

\section{Physical Properties.}

Although the mineral of Siberia be very similar in appearance to that of $\mathrm{Var}$, an attentive examination of it would lead us to suspect, that in the first of these the metal is purer and more abundant than in the second; its

* From Anantes de Mus sim d'Histoire Naturelle, No. 35.

Vol. 24. No. 93. Fel. 1806.

A 2

fracture 
fracture is lamellar, and not granulated; its metallic brilliancy is more vivid, and it evidently contains a smaller admixture of earthy matters. The specimen in my possession shows spots of green on some parts of its surface, which are discovered to be oxide of chrome. The specific gravity of the two also serves to support my conjecture regarding them. That of my specimen is 4.0579 , while the specific gravity of the mineral of Var is only 4.0326 . This difference in weight necessarily makes a difference in the proportions of the metallic part of the two chromates; and, as we shall presently see, the analysis agrees completely with this physical property.

\section{Chemical Examination.}

1. When strongly calcined it loses about 1-100th part of its weight, and acquires a reddish brown colour. Having placed 100 parts of this mineral reduced to an impalpable powder, together with 300 parts of pure potash, in a crucible of platiua, I exposed the whole to a strong heat. The mass, when removed from the fire, and nearly cooled, was in part of a green and in part of an orange colour. The water which I added to it assumed a rich citron yellow, exactly similar to the colour of chromate of potash. When the mass no longer gave a tinge to distilled water, I digested it in very weak muriatic acid, with the intention of separating what part of the oxide of iron had been set free by the action of the potash, without touching, in any degree, the chromate of iron, which was still undecomposed. I now washed the remaining substance again, till the water came off insipid, and a second time melted it with a portion of pure potash.

In this way I heated the mincral six different times, altemately with potash and muriatic acid; setting aside the alkaline and acid solutions, that I might examine them separately.

The residuum consisted of a.brownish gray matter, weighing 0.90 : muriatic acid took up from it a little iron, and the renainder was completely dissolved in nitro-muriatic acid. 
acid. This solution, which was of a redilish brown colour, let fall a yellow precipitate on the addition of muriate of ammonia, and a deep red precipitate by the muriate of tin at the minimum of oxidation: it suffered no precipitation by prussiate of potash, and formed with sodia a triple salt of a beautiful red colour. It was therefore no other than a portion of platina which had been separated from the crucible by the six successive manipulations ; and there was every reason to believe that the alkali and acid had completely dissolved the constituent ingredients of the mineral in question.

\section{Examination of the Alkaline Solution.}

2. This solution had a very beautiful reep yellow colour. The last portions of the solution had a greenish tinge, which disappeared on the spontaneous deposition of a brown substance in small quantity, which $I$ discovered to be oxide of manganese, I poured, by degrees, into the solution, evaporated to one-half its former bulk, such a quantity of nitric acid as saturated the caustic portion of alkali; and a precipitate fell to the bottom, which I collected upon a filter, then washed it, and submitted it to calcination. It weighed 11 hundredth parts, and was set aside for future examination.

The addition of a slight excess of nitric acid produced no precipitation but merely a violent effervescence, and caused the solution to assume a very deep orange red colour. When evaporated to dryness it left a saline residuum of a fine yellow colour, which dissolved completely in water : the solution, when acidulated with nitric acid, furnished by the nitrate of mercury a red precipitate, which after beirg dried in the air weighed 430 parts ; and these by calcination were reduced to 52 hundredth parts of an oxide of chrome, having a beautiful green colour.

3. The matter precipitated in No. 2 by the nitric acid was melted with three parts of caustic potash; and the mass, when mixed with water, dissolved completely in muriatic acid. The solution, when evaporated to dryness, 
left a residue, a part of which was insoluble in water, and weighed, after calcination, only one-half part : it consisted of a mixture of silica and oxide of iron. I now poured into the water which contained the soluble portion of the residuum a quantity of ammonia; and a white flocculent precipitate appeared, which formed with the water a jelly, and exhibited all the characters of alumine : it weighed 10 hundredth parts and a half.

From these experiments on the alkaline solution we may conclade that it contained chrome, alumine, a little oxide of manganese, together with some particles of iron and silica.

\section{Examination of the Muriatic Solution.}

4. The colour of this solution, which contained an excess of acid, was reddish yellow. On the addition of a solution of caustic potash a flocculent matter of a brownish red separated, which, when washed and mixed with the small quantity of oxide of iron already obtained, both from the alkaline solution and from the residue, discovered to be platina, weighed, after being calcined, 34 hundredth parts.

The solution continued still coloured after the separation of the oxide of iron, although the re-agents indicated the presence of no chrome: I was therefore convinced that it owed its tinge to a small quantity of platina. The excess of caustic potash which I had added contained some particles of alumine, and these I separated hy means of muriate of ammonia.

5. With a view to ascertain the purity of the oxide of iron which had the usual colour and appearance of this oxide, I melted it again with pure potash : but water, when added to the mixture, received no tinge, and the re-agents indicated the presence of no foreign substance. We must therefore infer that the very weak muriatic acid which I made use of diszolved nothing but the oxide of iron. 
From the above analysis it appears that the chromate of iron of Siberia contains in the 100 parts,

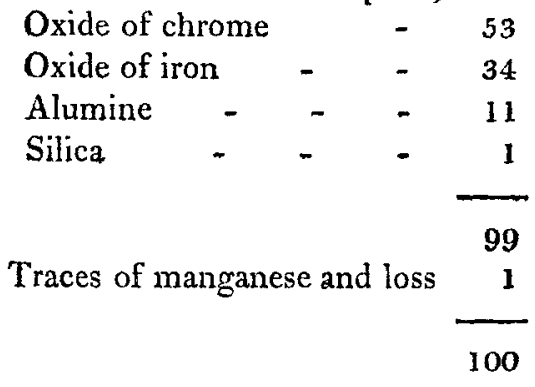

These results are nearly similar to what $M$. Vauquelin obtained from the chromate of Var.

\begin{tabular}{lccc} 
Chromic acid & - & - & 43 \\
Oxide of iron & - & - & $34 \cdot 7$ \\
Alumine - & - & - & $20 \cdot 3$ \\
Silica - & - & - & 2 \\
\hline & & & 100
\end{tabular}

Does the chrome exist in the state of acid or in that of oxide in the mineral termed chromate of iron? M. Godon de Saint-Mesmin, in a memoir upon the combinations of chromic acid, read at the National Institute, has discussed this question, and is inclined to think that it is in the state of oxide. M. Vauquelin, in his report of this memoir, seems disposed to adopt the same opinion. I shall merely state, in support of this idea, an experiment which renders it probable. If the green oxide of chrome be gently calcined with pure potash, it is almost immediately brought to the state of an acid: we are therefore not warranted in asserting that chrome exists as an acid in the chromate of iron, while by the presence of patash this conversion of the oxide is rendered likely. It is then, at least, highly probable that the mineral which till now has received the name of chromate of iron, is, in fact, no other than a combination of the oxides of iron and chrome.

Since I finished my examination of the chromate of iron A 4 
of Siberia, I have learnt that M. Lowitz has also analysed this substance. I am ignorant of the exact proportions of its ingredients, according to his experiments, but if I may judge from the note relative to this subject which appeared in the Journal de Physique, his results were nearly the same with mine; for he announces that he found it to contain more than half its weight of oxide of chrome, together with iron, alumine, and a little silica.

II. On the Tendency of Elastic Fluids to Diffision through each other. By John Dalton*

$I_{N}$ $I_{N}$ an early period of pneumatic chemistry it was discovered that elastic fluids of different specific gravities being once difused through each other, do not of themselves separate, by long standing, in such manner as that the heaviest is found in the lowest place; but, on the contrary, remain in a state of uniform and equal diffusion.

Dr. Priestley has given us a section on this subject (vịde Experiments and Obseivations, \&c. abridged, vol. ii. p. 441), in which he has proved the fact above mentioned in a satisfactory manner; and every one's experience since, as far as I know, has coincided with his conclusions. $\mathrm{He}$ has not offered any conjecture concerning the cause of this deviation from the law observed by inelastic fuids; but he suggests, that " if two kinds of air of very different specific gravities were put into the same vessel, with very great care, without the least agitation that might mix or blend them together, they might continue separate, as with the same care wine and water may be made to do."

The determination of this point, which seems at first view but a trivial one, is of considerable importance; as from it we may obtain a striking trait, either of the agreement or disagreement of elastic and inelastic fluids in their mutual action on each other.

It is therefore the subject of the following experiments to ascertain whether two elastic fluids, brought into contact,

* From Manchester Transactions, second series, vol. i.

conles 